\title{
分散型歩行制御によるムカデ型多脚歩行ロボットの高機動性の実現
}

\section{Highly-Mobile Centipede-Like Multi-Legged Robot based on Decentralized Control}

\author{
○正 稲垣 伸吉（名古屋大），非 丹羽 智也（名古屋大），正 鈴木 達也（名古屋大） \\ Shinkichi INAGAKI, Nagoya University, inagaki@nuem.nagoya-u.ac.jp \\ Tomoya NIWA and Tatsuya SUZUKI, Nagoya University
}

\begin{abstract}
This paper addresses on decentralized walking control of multi-legged robots based on Follow-theContact-Point (FCP) gait control and averaging control of leg contact force. These control schemes realize gait control and navigation control on uneven terrain simultaneously with perfectly decentralized manner. In this paper, we introduce the control laws and show its availability by using a physical simulation of centipede-like multi-legged robot.
\end{abstract}

Key Words : Multi-Legged Robot, Uneven Terrain Walking, Decentralized Control, Event-Driven Control, Averaging leg contacting force

1.は じめに

多脚歩行ロボット（6 脚以上の脚を持つ歩行ロボット） は高い安定性による優れた不整地踏破性能と，圥長自由 度による高い耐故障性能という特徴を持つ。その中でも， Fig.1のようなムカデ型多脚歩行ロボットは, 多脚歩行ロ ボットとしての特徵に加え, 蛇型ロボットのような高い 環境適応能力を併せ持つものと期待される。

これまで，その歩行制御においては，隣接する脚間で 一定の位相差を保つことを目的とした制御法 (事象駆動 型制御 ${ }^{(1)}$ ，Central Pattern Generator (CPG) を用いた制御 (2)(3) $)$ が提案されている。しかし，不整地での歩行を実 現するには至っていない.

これに対し筆者らは，接地点計画に基づく多脚歩行口 ボットの不整地歩行制御を，分散制御により実現する「接 地点追従法; Follow-the-Contact-Point (FCP) gait control」 を提案している ${ }^{(4)}$. 接地点追従法は, 最前脚が接地した 点（接地点）に，後に続く脚が必ず接地するという実際 のムカデの行動学的知見 ${ }^{(5)}$ に基づいた方法であり，各脚 は，隣接脚の状態に基づいて制御モードを切換える事象 駆動型制御に基づき制御される。

接地点追従法では脚先を接地点に維持することが，機 動性能を向上することに重要であることから，本論文で はさらに脚先に働く反力の平均化に基づく脚先高さの制 御を導入する。そして，物理シミュレーション環境に構 築したムカデ型多脚歩行ロボットに接地点追従法を適用 し，その実験結果について述べる。

\section{2. セグメントと制御域の定義}

Figure 2 のように，体節と左右の脚，および前方の体節 とつながるリンク (体節間リンク) を合わせて一つのセ グメントとして，3セグメント以上（つまり，6 脚以上） で構成されているロボットを考える。

セグメント $i \in\{1, \cdots, N\}$ における, 左 $(l)$ と右 $(r)$ の各

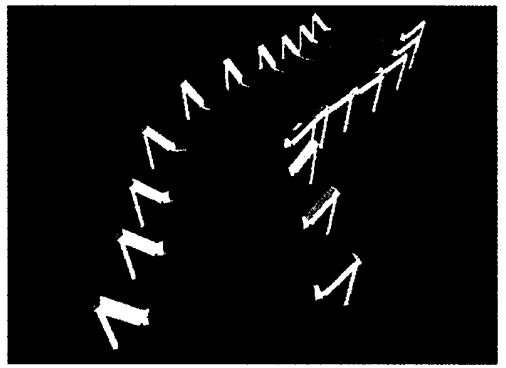

Fig. 1 Multi-legged robot in simulation environment

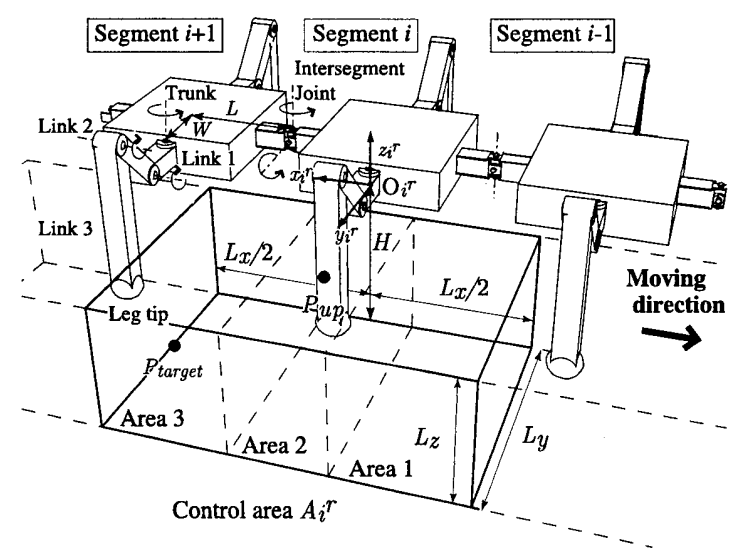

Fig. 2 Segments and control area

脚に対し, その付け根に原点を持つ座標系 $C_{i}^{s}=\left(x_{i}^{s}, y_{i}^{s}, z_{i}^{s}\right)$, $s \in\{l, r\}$ を定義する.そして，この座標系 $C_{i^{s}}$ を持つ脚の 脚先の可到達域を $M_{i}^{s}$ としたとき，制御域 $A_{i}^{s} \subset M_{i}^{s}$ を定 義する。ここで，制御域は各脚の座標系に固定された領 域であり，ロボットの進行にあわせて制御域も移動する ことに注意されたい。 


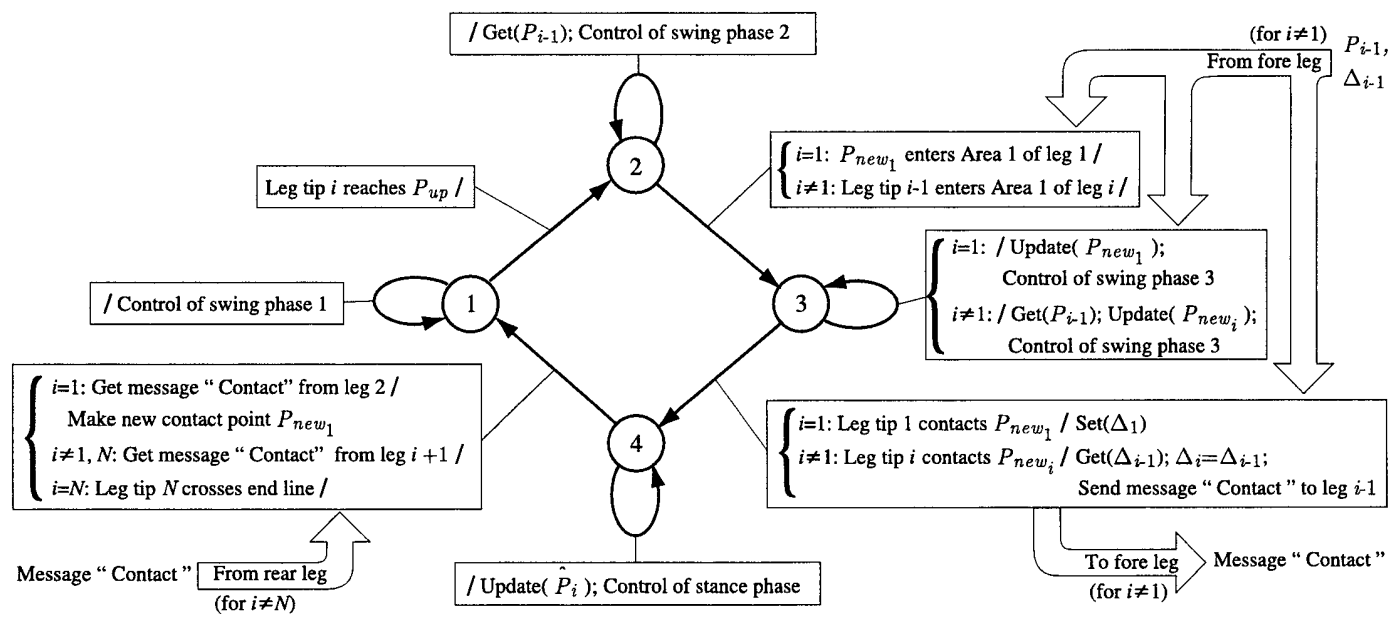

Fig. 3 Automaton of leg control in FCP gait control

制御域 $A_{i}^{s}$ は，前後に接続された体節の姿勢に応じて， 次の，多くて 3 つの領域に分けることができる.

Area 1: 制御域 $A_{i-1}^{s}$ と重なる領域,

Area 2: 重なりがない領域,

Area 3: 制御域 $A_{i+1}^{s}$ と重なる領域。

以降では，表記を簡単化するために，変数の「左・右」 を表す添え字 $s \in\{r, l\}$ を，必要がない限り省略する。

\section{3. 接地点追従法}

本節では，接地点追従法（Follow-the-Contact-Point (FCP) gait control) について概要を述べる。詳細は文献 (4)を参照されたい。

$3 \cdot 1$ 各脚の制御モード接地点追従法では，遊脚相 と接地相のそれぞれにおいて，脚先を目標位置に収束さ せるように各モー夕を制御する。この制御は次のような PD 制御により実現できる。

$$
\tau_{m}=K_{p}\left(\hat{\theta}_{m}-\theta_{m}\right)-K_{d} \dot{\theta}_{m} .
$$

ここで, $\tau_{m}$ は脚のモータ $m \in\{1,2,3\}$ のトルクであり, $\theta_{m}$ はその角度, $\hat{\theta}_{m}$ は目標角度, $K_{p}, K_{d}$ は正定数である。 目標角度 $\hat{\theta}_{m}$ は，次に説明する各制御モード（遊脚相が制 御モード 1 - 3 , 支持脚相がモード 4 に対応）において設 定される, 脚先の目標位置の逆運動学より計算される。

制御モード1 (接地点からの離脱)：制御モード 1 では, 脚先を接地点から離し, 空中の中間点 $P_{u p}$ に向かって動 かす。(1) 式における目標角度 $\hat{\theta}_{m}$ は， $P_{u p}$ の逆運動学によ り求められる。

制御モード 2 (中間点での停留)：制御モード 2 では, 脚 $i$ の脚先を, 前方脚 $i-1$ の接地点が, 脚 $i$ の制御域におけ るArea 1 に入るまで，中間点 $P_{u p}$ に待避させる，ただし， 最前脚 $(i=1)$ については，新たな接地点となる点を進 行方向前方の地面に生成し，その点が脚 1 の制御域にお けるArea 1 に入るまで，中間点 $P_{u p}$ に待避させる。この 場合も, (1) 式における目標角度 $\hat{\theta}_{m}$ は, $P_{u p}$ の逆運動学に より求められる。

制御モード 3 (新接地点への接近)：制御モード 3 では, 脚 $i$ の脚先を，新たな接地点 $P_{\text {new }}$ に向かって動かす。最 前脚 $(i=1)$ の新たな接地点は，制御モード 2 において
進行方向前方に生成した点である。それ以外の脚 $(i \neq 1)$ については, 前方脚 $i-1$ の接地点の, 脚先の大きさの分 だけ後方にずらした点が新たな接地点となる。

制御モード 4 (推進力の生成)：脚先 $i$ が次の接地点 $P_{\text {new }}$ に接地後，次式の目標点を各時刻において計算する。

$$
\hat{P}_{i}=P_{i}+\frac{\Delta_{i}}{\left|P_{\text {target }}-P_{i}\right|}\left(P_{\text {target }}-P_{i}\right)
$$

ここで， $\Delta_{i}$ は目標点の変化速度， $P_{\text {target }}$ は限界目標点, $\left|P_{A}-P_{B}\right|$ は 2 点 $P_{A}$ と $P_{B}$ の間の距離を表す。限界目標点 は制御域の端点であり，ここに達するまでに支持脚は遊 脚に移る必要がある。

目標点の変化速度 $\Delta_{i}$ はロボットの移動速度を調整する パラメータである. $\Delta_{i}$ は前脚 $i-1$ から接地点を引き継い だ時に， $\Delta_{i}=\Delta_{i-1}$ と更新する. 支持脚 $i$ が遊脚に移る夕 イミングは, 後脚 $i+1$ が脚先 $i$ の接地点を受け継いだ瞬 間である．最後脚については脚先がある位置を超えた瞬 間に遊脚する。この制御モードでは，(1)式に扔ける目標 角度 $\hat{\theta}_{m}$ は, $\hat{P}_{i}$ の逆運動学から求まる。

3.2 制御モードの遷移接地点追従法における各脚 の制御モードの遷移は，事象駆動型の状態遷移図により 記述できる. Figure 3 は, 各脚の制御モードの切り替えを 表す，Mealy 型のアートマトンである.

Mealy 型オートマトンにおける状態遷移は,

$$
\text { inEvent }[\text { guard]/outEvent; ...; outEvent }
$$

と書くことができ，入力イベント“inEvent”が発生し，ガー ド条件“guard”が成り立つとき，状態遷移と共に，出力イ ベント “outEvent”を発生する(6). それぞれの項目は省略 することができ，特に，入力イベントもガード条件も省 略されている場合 $(/ \cdots)$ は，常に状態遷移と出力イベン トの生成が行われる。また，出力イベントが省略されて いる場合 $(\cdots /)$ ）は，遷移のみが行われる。遷移のチェッ クはロボットの制御周期毎に行われるものとし，入力イ ベントもガード条件も省略されている遷移と，入力イべ ントが省略されていない遷移の発火条件が同時に満足す る場合は，省略されていない遷移を優先するものとする， Figure 3 において，最前脚 $(i=1)$ ，中間脚 $(i \neq 1, N)$, 最後脚 $(i=N)$ では，隣接するセグメントの関係により， 


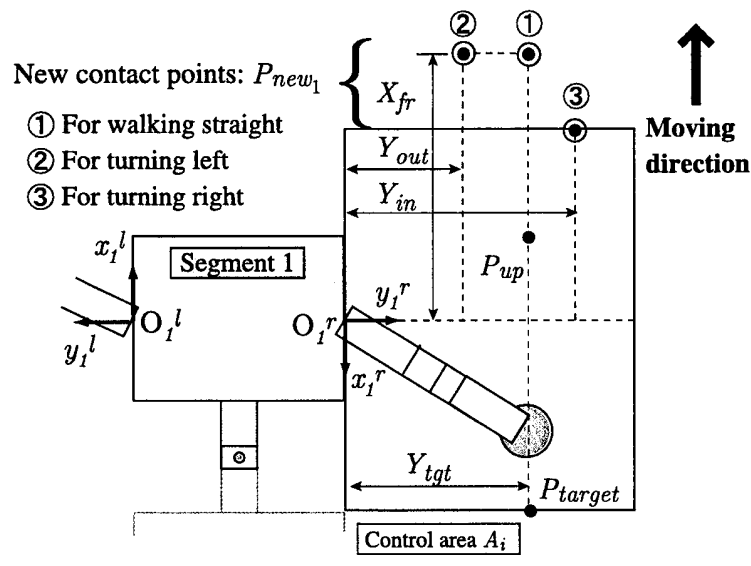

Fig. 4 New contact point of first leg

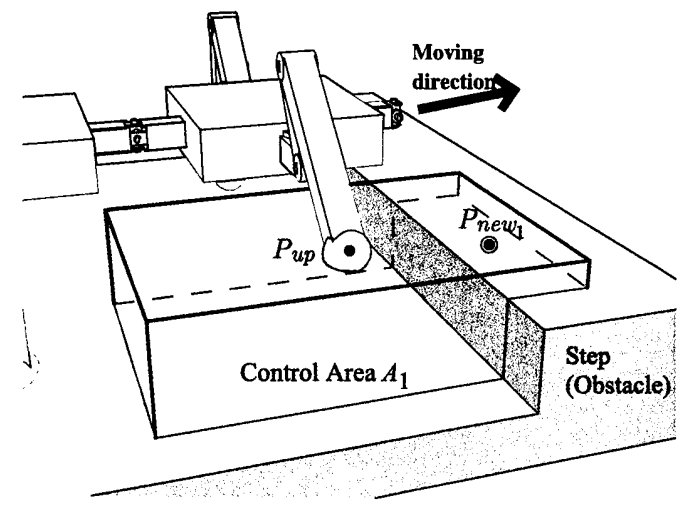

Fig. 5 New contact point of first leg to get over obstacle

制御アルゴリズムが違っていることに注意されたい。こ の制御アルゴリズムから, 各脚 $i$ は, 前方の脚 $i-1$ から 接地点の座標 $P_{i-1}$ と目標点の変化速度 $\Delta_{i-1}$ を, 後方の 脚 $i+1$ から接地を示すメッセージを受け取るだけでよく， 近接の脚の情報のみを用いるという点で分散制御が実現 できていることが分かる．接地点追従法では，各脚にお いて Fig.3のオートマトンを並列して実行する.

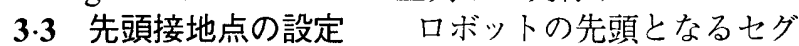
メントは, 進行方向の地面上に新しい接地点 $P_{\text {new } 1}$ を作 る。新しい接地点 $P_{\text {new } 1}$ の配置の仕方によって，ロボット の進行方向を制御でき（Fig.4），また，障害物上に配置 することで障害物の乗り越えが可能となる（Fig.5）.

また，進行方向の制御においては，進行方向に応じた 新しい接地点の接地と共に, 目標点の変化速度 $\Delta_{1}$ を左右 で別の值に設定する。つまり，曲がりたい方向側の脚に おける目標点の変化速度 $\Delta_{1}$ を小さく, 逆側の值を大きく する。

\section{4. 接地点追従法のシミュレーション結果と問題点}

提案手法を検証するために，物理シミュレー夕 PhysX [www.nvidia.com] を用いた. Figure 1 は，シミュレータ環 境内に構築したロボットであり，10セグメント，つまり 20 脚により構成されている。このロボットの歩行制御と して接地点追従法を用い, 制御周期 10 [ms], シミュレー ションのサンプリングタイム $1[\mathrm{~ms}]$ として検証を行った.

Figure 6 は平地において最前脚の接地点を Fig.4のよう
(1) Walking Straight, (2) Truning left, (3) Truning right

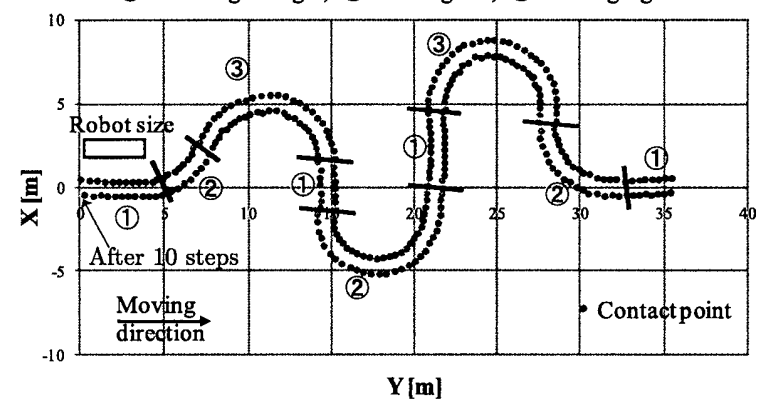

Fig. 6 Operation performance
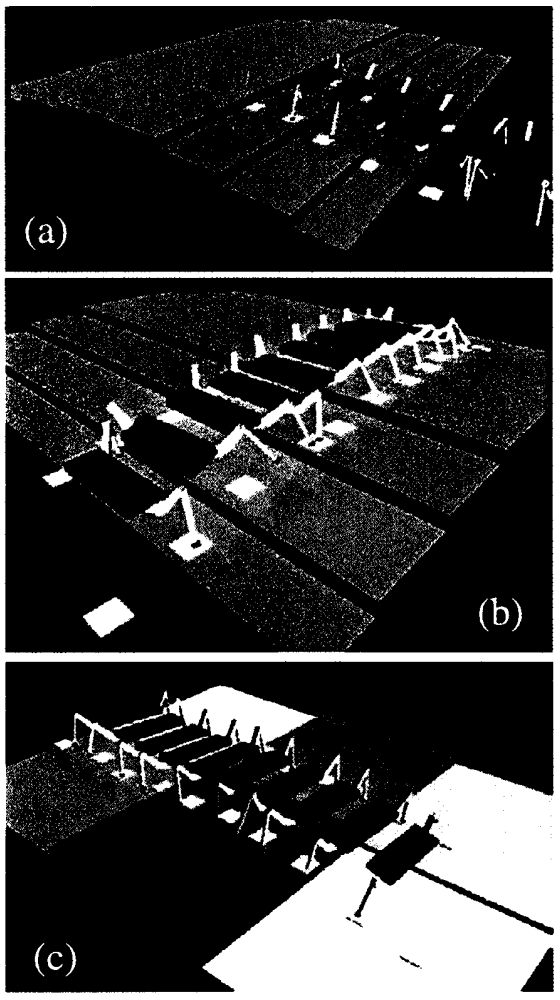

Fig. 7 Simulation result of 10 segments robot: (a) (b) going up and down stairs, (c) walking through tiled uneven ground

に切換える事で，前進，右折，左折を行った結果である。 図中の点は先頭のセグメントが生成した接地点を表し，接 地点を切り替えた箇所が線分で示したある。なお，接地 点の切換は操作者が行った。

次に, Figure 7 に, (a)(b)1 段の高さがロボットの地面か ら胴体までの高さの半分である階段の乗り越え実験, (c) 同じ段をタイル状に並べた障害物の踏破実験の様子を示 す。図中の地面上の四角は，先頭のセグメントが生成し た接地点である。いずれの場合も，障害物を踏破するこ とができた。しかしながら，特にタイル状の障害物など， 左右の脚で接地する地面の高さが違うときなどに，接地 相にある脚先が接地点を離れてしまい推進力が得られず， 前進できないという問題が生じた。次節ではこの問題を 解決するために，接地相にある脚の間で接地加重を平均 化する分散制御を提案する。 

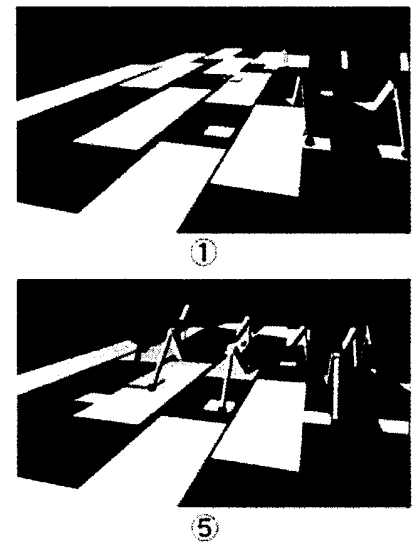
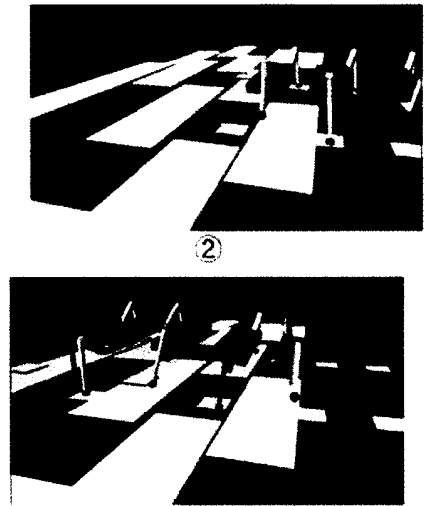

(6)

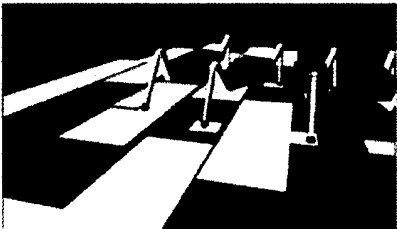

3

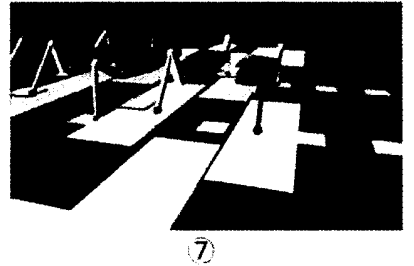

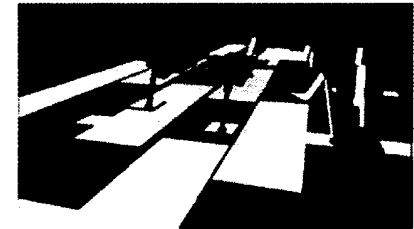

(4)

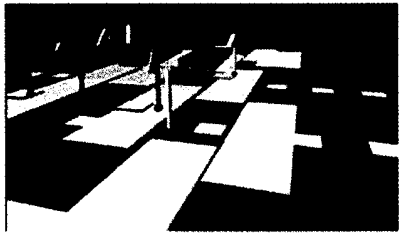

(8)

Fig. 85 segments robot walking over tiled obstacles with implementation of averaging contacting-force

5. 分散制御に基づく脚先反力平均化制御

接地相つまり制御モード 4 における脚先の目標点を (2) 式の代わりに次式とする.

$$
\hat{P}_{i}=P_{i}+\frac{\Delta_{i}}{\left|P_{\text {target }}-P_{i}\right|}\left(P_{\text {target }}-P_{i}\right)+\alpha\left(F_{d i}-F_{i}\right) \vec{e}_{z}
$$

ここで, $\alpha$ は正定数， $F_{d i}, F_{i}$ はそれぞれ脚 $i$ の目標床反 力と床反力, $\vec{e}_{z}$ は脚 $i$ の座標系における $z$ 方向単位べク トルである。つまり, 接地相において脚先が床から適当 な反力を受けるように脚先高さをフィードバック制御す ることにより，脚先を床から離れないように制御するの である. 目標床反力の導出については接地脚間での床反 力平均化に基づく方法 ${ }^{(7)}$ が提案さ机ているが， ムカデ型 多脚歩行ロボットでは不良設定問題への対応が困難であ る. そこで, 拡散方程式 (Diffusion equation) に基づく各 モジュールにおける局所演算により，接地脚間での平均 床反力を算出する。

まず，各制御周期における各セグメント $i$ の接地相（制 御モード 4) にある脚数を $X_{i} \in\{0,1,2\}$ とする. そして, 制御周期を分割した時間 $\tau=(0, \cdots, T)$ に扔いて平均接地 脚数 $x_{i}(\tau)$ を次の発展方程式を計算する。 $i=1,2, \cdots, N$ に対して,

$$
\begin{aligned}
x_{i}(0) & =X_{i} \in\{0,1,2\}, \\
\frac{d x_{i}(\tau)}{\tau} & =\sum_{j=\{i-1 . i+1\} \backslash\{0 . N+1\}}\left(x_{j}(\tau)-x_{i}(\tau)\right) \\
& \text { for } \tau=1, \cdots, T
\end{aligned}
$$

そして, 次の制御周期の目標床反力を次式から算出する.

$$
F_{d i}=M_{\text {seg }} / x_{i}(T) .
$$

ここで， $M_{\text {seg }}$ はセグメントの重量である. 脚先反力平均 化制御を搭載した場合のシミュレーション結果を Fig.8に, 各セグメントの平均接地脚数を Fig.9に示す. タイル状不 整地でも接地を維持し，前進できていることが分かる。

$$
\text { 6.おわりに }
$$

本稿では，ムカデ型歩行ロボットの分散型歩行制御法 として, 接地点追従法に分散制御に基づく脚先反力平均

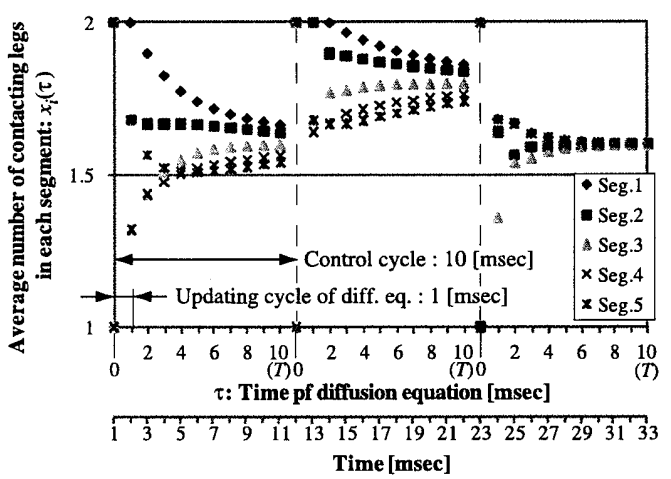

Fig. 9 Update of average number of contacting legs in each segment based on diffusion equation

化制御を導入し，物理シミュレータを用いて不整地踏破 が可能であることを示した。最前脚接地点の計画法，実 機開発が今後の課題である.

\section{文献}

(1) A.Torige, S.Yagi, H.Makino, T.Yagami, N.Ishizawa "Centipede type walking robot (CWR-2)," Proc. of IEEE/RSJ Int. Conf. on Intelligent Robots and Systems, pp.402-407, 1997.

(2) S.Aoi, H.Sasaki, and K.Tsuchiya: "A multilegged modular robot that meanders: investigation of turning maneuvers using its inherent dynamic characteristics," SIAM J. on Applied Dynamical Systems, Vol.6, No.2, pp.348-377, 2007.

(3) L.Matthey, L.Righetti and A.J.Ijspeert: "Experimental study of limit cycle and chaotic controllers for the locomotion of centipede robots," Proc. of IEEE/RSJ Int. Conf. on Intelligent Robots and Systems, pp.1860-1865, 2008.

(4) 稲垣伸吉, 丹羽智哉, 鈴木達也: “齐ットワーク型多脚歩行 ロボットの接地点追従法に基づく分散制御, ”計測自動制御 学会システム・情報部門学術講演会, pp.252-257, 2009.

(5) B.D.Anderson, R.J.Full, T.Chen, "Mechanics of locomotion in centipedes," American Zoologist, Vol.30, No.4, p.135A, 1990.

(6) 阪田史郎，高田広章: “組込みシステム,”オーム社, 2006.

(7) 米田完, 飯山浩幸, 広瀬茂：“4 足歩行機械のスカイフック サスペンション制御, ”日本ロボット学会誌, vol.12, no.7, pp.1066-1071, 1994. 